\title{
Kuwait University Faculty Usage and Perspectives of Reference Management Software
}

\author{
Batool A. Hendal \\ Information Studies Department, College of Social Sciences, Kuwait University, Kuwait City, Kuwait \\ Email: Batool.hindal@ku.edu.kw
}

How to cite this paper: Hendal, B.A. (2019) Kuwait University Faculty Usage and Perspectives of Reference Management Software. Open Access Library Journal, 6: e5685.

https://doi.org/10.4236/oalib.1105685

Received: August 8, 2019

Accepted: August 26, 2019

Published: August 29, 2019

Copyright $\odot 2019$ by author(s) and Open Access Library Inc.

This work is licensed under the Creative Commons Attribution International License (CC BY 4.0).

http://creativecommons.org/licenses/by/4.0/

\section{(c) (i) Open Access}

\begin{abstract}
The aim of this descriptive and quantitative study was to explore the usage of reference management systems (RMSs) among Kuwait University (KU) faculty and their perspectives towards using these systems. For this purpose, an online survey was distributed using Google Forms. The sample was all KU faculty from all the 16 colleges, and a link to the survey was sent by email to all the faculty. The results show a humble usage of RMSs among the faculty, EndNote is the most common software. The participants declared their need for both awareness of and training for the RMS packages; this need was declared by both users and non-users of RMSs. The results of this study will be beneficial for the KU library administration to be better engaged in the awareness campaign at the university level.
\end{abstract}

\section{Subject Areas}

Information Science, Information Retrieval, Library, Intelligence and Philology

\section{Keywords}

Reference Management Software, RMS, Bibliography Management Software, EndNote, RefWorks, Mendeley, Kuwait University, Faculty

\section{Introduction}

Citations and references play a significant role in any academic work. All academics and researchers have a common task in their writings, which is to cite and reference the resources they use in their work, regardless of their field or the type of resources (books, journals, websites, and social media) or even the refe- 
rencing style used (such as APA, MLA, Harvard style, and so on); otherwise, they will face plagiarism and intellectual property issues. Hence, Francese [1] referred to the bibliography as the spine of a scientific research work. Scholars depend on bibliographic references, and after consulting these references, they produce a new list in all their research productions. Reference listing requires no intelligence; as Rakhshan [2] claimed, this task seems extremely tedious and time consuming to all researchers and writers.

Fortunately, the impact of the computer that marks all our life sectors reaches libraries and research sectors as well. Nowadays, computer software facilitates the referencing process by importing precise citation records from official websites and inserting them into a database, sparing the author from repetitive and dull tasks related to reference listing. A variety of commercial and open source software programs are available nowadays, such as reference management software (RMS) or bibliographic management software and citation management tools, such as EndNote, RefWorks, Mendeley, JabRef, BibTex, and Zotero, just to mention few. Regarding Microsoft Word's referencing feature and the Google Scholar's cite feature, Roux and Burke [3] claimed that the referencing mechanism of the latter is mostly controlled by the publishers of the articles. Appendix 1 shows a comparison of RMSs by Roux and Burke [3].

\section{Reference Management Software}

The difference between reference management or citation management tools in general and RMS was clearly considered by Childress [4], who stated that a reference management tool is "any resource, program or service that supports citation management, or the understanding, gathering, organisation, and use of citations in research and information literacy" (p. 144). RMS, on the other hand, enables researchers to store, arrange, output, and share their references. Another RMS definition is by Lonergan "a software that stores citations in a digital form, either on a local computer or via an online interface, to make organizing research and formatting bibliographies and in-text citations more efficient" (p. 2) [5]. Thus, the key functions of RMSs are to create a citation database, with the ability to track and arrange the references, and to format references and citations while writing a document.

The usage of RMSs has been increasing among faculty, graduate students, and librarians. EndNote, for example, is available in most bookstores in North American universities. Twelve of the top 25 universities in the United States and four of the top 15 universities in Canada provide their clients with an EndNote site license as part of their services [6]. Moreover, the University of Torino has purchased 347 licenses for the software EndNote in 2008, to be disseminated among faculties who declared their interest in using RMSs [7]. Not only has the usage of RMSs been rising, but so have publications related to RMSs and RMS issues.

Several researchers examined the features of RMSs. Some researchers com- 
pared features between two software programs [3] [8] Other researchers compared more software. Hensley [9], for example, examined the features, benefits, and drawbacks of four popular RMSs-RefWorks, EndNote, Zotero, and Mendeley-from the perspectives of both librarians and patrons. Likewise, Gilmour and Cobus-Kuo [10] compared four RMSs-CiteULike, RefWorks, Mendeley, and Zotero-in terms of their features and accuracy of generated bibliographies. Further researchers studied the reliability and accuracy of RMSs.

Other researchers concentrated on RMSs and libraries and librarians. East [11] examined the role of academic libraries in Australia and the provision of support for RMS users; a high level of support is provided by these libraries. Childress [4] concentrated in detail on the skills and practices that librarians and staff should implement in terms of RMS.

\section{Related Literature}

Several researchers investigated the usage and awareness of RMSs among faculty in different countries. However, the number of studies concentrating this issue is relatively unpretentious compared to the number of studies addressing the features and packages of RMSs.

In India, two different studies investigating faculty awareness of RMSs were conducted, and both of them concentrated on library and information studies (LIS) professionals. The first one was by Ram and Anbu K. [12], who investigated the awareness of RMS packages and the commonly used software in LIS in India. Their sample included students, teachers, and LIS professionals. Their results showed that over half of the sample never used RMSs (54.63\%), 6.62\% knew of RMSs but never tried any software, $27.75 \%$ used it when needed, and $10.96 \%$ used it frequently. The most widely known RMS package was Reference Manager (41.87\%), followed by EndNote (15.29\%). Their study confirmed a need for strengthening the awareness of RMSs at the institutional level.

The second study in India was by Parabhoi, Sahu, and Bhoi [13]. They also concentrated on LIS professionals and evaluated the usage of RMSs. They found that professionals in India were well aware of RMSs; 59.37\% used RMSs, and $40.62 \%$ did not. The most used referencing style is APA, and $76 \%$ of the sample indicated their need to have training on RMS usage.

Frances [1] [14] investigated faculty awareness and usage of RMSs at two universities in two different countries. In Tallinn University in Estonia, Frances [14] observed a general awareness among the scholars at the university, but the rate of non-RMS users was high: $44 \%$ declared not using any software, although the library provides a license and support for RefWorks. The other study by Frances [1] was at the University of Torino, Italy, where the awareness of RMSs was also high: Only $8 \%$ of the faculty declared not knowing any software. The majority used RMS tools (75\%), and the most used software was EndNote.

In the United States, Lonergan [5] investigated the preferences and attitudes towards RMSs among the Liberal Arts faculty. Of the respondents, $43 \%$ did not 
use RMSs. The RMS users used several tools: Zotero, Endnote, RefWorks, and BibTex. Although the library supports RefWorks, the majority of faculty preferred Zotero.

Sarrafzadeh and Hazeri [15] investigated the familiarity with and usage of RMSs by LIS faculty in Iran. Their results indicated that over half of the participants were familiar with the RMS tools and knew how to use them. The most common software was EndNote. The respondents indicated a need for training programs on how to use RMS packages for the undergraduate students, and they recommended a particular course dealing with academic writing to teach the students the required RMS skills. In another study in Iran, Sarrafzadeh and Khaleghi [16] concentrated on the RMS training and support provided by academic libraries. They investigated the websites of Iranian universities, and the results showed that about $50 \%$ of Iranian universities do not include any information about RMS tools. The central library at 39\% of the universities was responsible for introducing RMSs to the faculty and providing training. EndNote was the only RMS software supported by all universities.

In Istanbul, particularly at Istanbul University, Yildirim and Yilmaz [17] examined the usage of RMSs by the faculty. The outcomes revealed the faculty did not use any RMSs; however, they clearly indicated their need for RMSs and their desire to use these tools if provided. Among the desired features of these tools if provided, they preferred an affordable and easy-to-use software.

\section{Methodology}

In this paper, the aim was to examine the usage of RMSs among Kuwait University (KU) faculty and their attitudes towards such tools. The significance of this study is to explore their awareness and their preferred software and features, in addition to understanding the reasons for not using RMSs and examining the role of the KU library administration in this process, based on the results. Specifically, the aim is to answer the following questions:

- To what extent does the KU faculty use RMSs?

- Which RMS software is preferred among KU faculty?

- What are the reasons for not using RMSs?

\subsection{Design}

An online survey was created using Google Forms and adopted Lonergan's [5] questionnaire with slight modifications to better match the purposes of this study. The questions were in both Arabic and English because Arabic is the main language at KU. The sample was divided into two groups according to their survey answers: Group 1 included RMS users, and Group 2 included non-RMS users. An email was sent to all faculty in July 2019 using the official email addresses, in cooperation with the office of vice president of the Research Sector at KU. KU has 16 colleges, all of which were included in this survey, except the Graduate Studies College because the faculty of this college are from the 16 other 
colleges. All the academic ranks at KU were included as well: professors, associate professors, assistant professors, teaching assistants, language instructors, and clinical instructor.

The statistics and data charts were imported using online Google Forms and Microsoft Office Excel (version 16.27).

\subsection{Approach}

A descriptive quantitative approach was used for this study. According to Yilmaz [18], quantitative research "seeks to develop explanatory universal laws in social behaviours by statistically measuring what it assumes to be a static reality" (p.312). The main benefit of this approach is that it enables the researcher to measure answers of a number of contributors to identify the general pattern of the contributors' feedback towards a particular treatment or program. Therefore, the quantitative method enables researchers to acquire generalised findings to represent the examined society.

\subsection{Originality and Implication}

Based on the author's knowledge, this is the first study to examine RMS awareness and preferences at KU. This study will be beneficial for KU administration, and particularly KU library administration, in understanding the faculty awareness of RMSs and their need for training and software packages.

\section{Results}

The total number of responses received was 101 from both genders equally, 51 females and 50 males. The sample represents 14 colleges; unfortunately, there were no participants from two colleges: the College of Dentistry and College of Architecture. As shown in Figure 1, the highest percentage of responses was received from the College of Education $(33.7 \%=33)$, followed the College of Engineering and Petroleum $(17.8 \%=18)$, the College of Social Sciences $(14.9 \%)$, College of Sciences (12.9\%), College of Arts (5\%), College of Computing Sciences and Engineering (4\%), and the College of Medicine and College of Business Administration (both 3\%). Only one response (1\%) was received from six colleges: the College of Law, College of Sharia and Islamic Studies, College of Allied Health Sciences, College of Life Sciences, College of Pharmacy, and College of Public Health.

People from all academic ranks at KU participated in this survey. Figure 2 illustrates the number of individuals of each academic rank. The highest rate of participation was by assistant professors $(32 \%=33)$. Teaching assistants made up $31 \%$ and associate professors $23 \%$. Twelve professors participated, whereas only one response was received from the clinical instructor group. Similarly, one language instructor participated.

The question about faculty RMS usage came after the three demographic questions and divided the participants into two main groups: RMS users and 


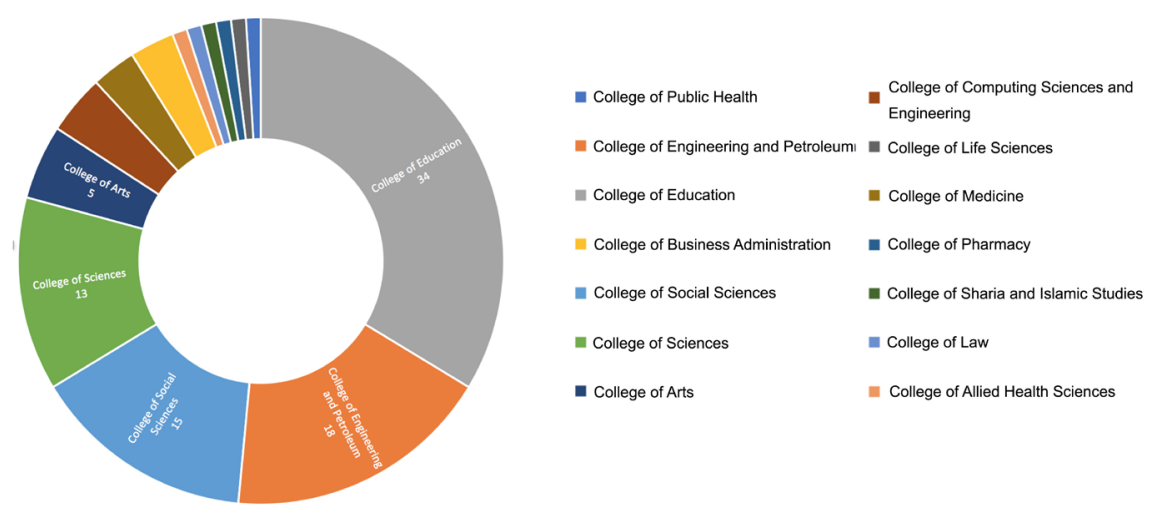

Figure 1. Participants' college distribution.

\section{Academic Ranks}



$$
\begin{aligned}
& \text { - Professor } \quad \text { - Associate Professor } \text { - Assistant Professor } \\
& \text { - Teaching Assistant } \quad \text { - Language Instructor }=\text { Clinical Instructor }
\end{aligned}
$$

Figure 2. Participants' college distribution.

non-RMS users. Of the respondents, over half of the sample did not use RMSs; $57.4 \%$ confirmed not using RMSs, whereas $42.6 \%$ used these tools.

\subsection{Group 1: RMS Users}

Different tools were selected by the participants. EndNote was the most popular software program among the faculty, with $29 \%$ using EndNote or EndNote web. Mendeley and RefWorks were about the same: 10 participants were Mendeley users, and nine chose RefWorks. Six participants used BibDesk/BibTex, whereas there was only one user for each of Reference Manager, Zotero, and Microsoft Word Reference. Another tool, DropBox, was added by one of the users, though it was not listed (Figure 3).

When asked about their preferred features of the RMS tools they use, participants selected several features. The two most significant features, which were selected equally by 34 users (79.1\%), were importing references from databases and organising and searching for references. Creating a formatted bibliography was also considered a major feature $(58.1 \%=25)$, followed by a plug in for Microsoft Word or any other word processor to format citations and bibliographies 


\section{RMS used by KU Fauclty}

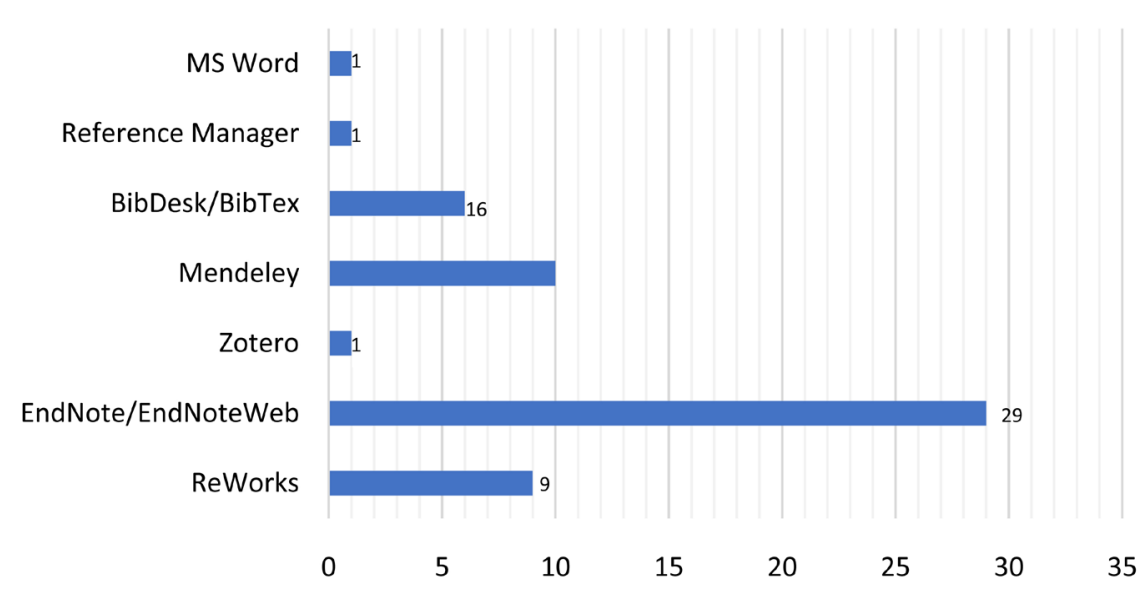

Figure 3. Reference management system (RMS) tools used by Kuwait University (KU) faculty.

while you write $(53.5 \%=23)$ and automatically generating a reference entry from an uploaded PDF $(27.9 \%=12)$. Lastly, annotating and highlighting uploaded documents and collaborating on documents and reference lists with others were the least preferred features, both of which were selected equally by 10 users (23.3\%).

Participants were also asked, "Have you attended any RMS workshop organised by the KU library administration?" Of the RMS users, 76.3\% (33 out of 56) stated that they had not attended any workshop organised by the KU library administration. Only nine faculty members had attended these workshops (21.4\%).

The last question for Group 1, also offered to Group 2, was about their desire to know more and to attend workshops about RMS packages. Although all faculty members in this group were actual RMS users, $72.1 \%$ (31) of them indicated their desire to know more and to attend workshops about these tools, whereas $27.9 \%$ (12) were not interested in attending any RMS workshops.

\subsection{Group 2: Non-RMS Users}

There were various reasons behind the reluctance of this group to use RMS tools (Figure 4). The most reasonable obstacle was unawareness of these tools. The majority confirmed their unfamiliarity with any of the RMS tools $(58.6 \%=34)$, whereas five respondents $(8.6 \%)$ indicated their ignorance on how to use any of these tools and $25.9 \%$ (15) believed these tools are complicated and preferred the classic way of referencing. These were the options provided in the question, but four more barriers were added by the participants:

1) Sometimes these tools organise the references accurately, but not always, and they do not necessarily follow the requirements of the selected journal or publisher.

2) I have attended several workshops, but I found them all useless. 

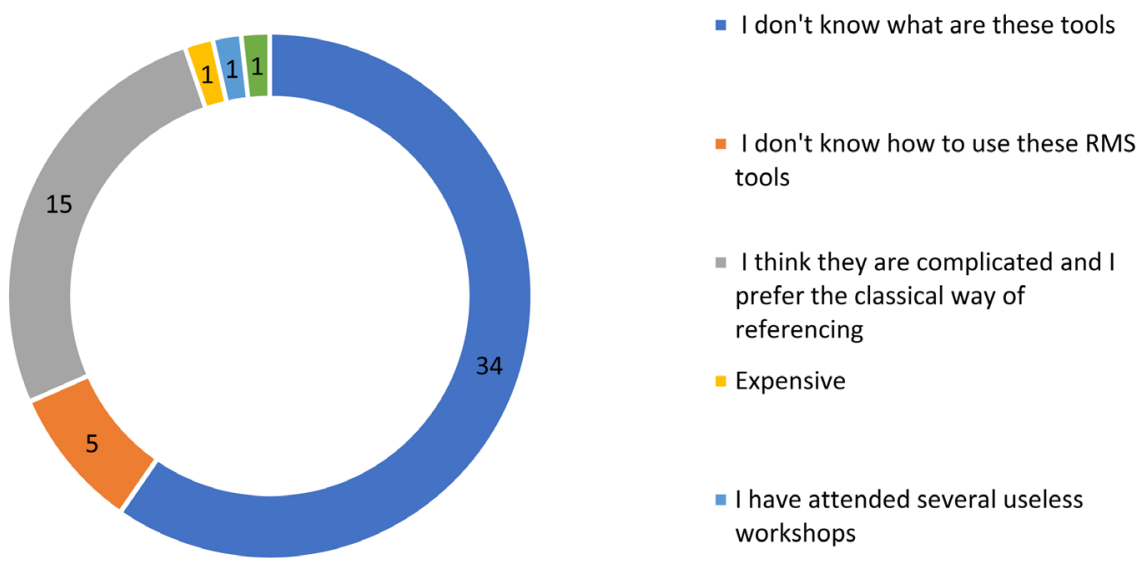

Figure 4. The reasons for not using reference management system (RMS) tools by Kuwait University (KU) faculty.

3) I do not need any software.

4) The tools are very expensive.

The last question, similar to the question for Group 1, was about participants' willingness to know about RMS and attend training workshops. Most answered this question positively and exposed their need to know and learn more about RMS tools $(89.7 \%=52)$, whereas six respondents $(10.3 \%)$ stated that they do not need to know more or attend any RMS workshops.

\section{Discussion and Conclusions}

The foremost result of the collected data is the low percentage of RMS users among KU faculty, mainly because they are unaware of these tools and how to use them. Some expressed the complexity of these tools and their preferences to stick with the routine way of referencing and citation, as well as the high price of such tools. However, the latter two reasons indicated a serious need for awareness and training sessions, first, because there are several alternative tools a user can choose from. If one finds a particular software that is complicated or difficult, he or she can choose a simple and easy-to-use program; people just need to be exposed to the options they have. Second, stating the high price of these tools as a reason not to use them shows unawareness of KU library services, particularly the fact that the KU library administration basically offers a free license and support for some tools as part of the KU subscription to the providers' databases, such as Scopus and Clarivate Analytics, previously known as Thomson Reuters. Hence, all KU affiliates are able to use (online) and download some tools, such as Mendeley and EndNote.

Another significant finding is that Endnote was the most popular software used by KU faculty, which matches several studies mentioned earlier such as the popularity of EndNote in United States and Canada [6], in Italy, Frances [1], and in Iran [15].

Lastly, one reason that might be a main barrier for using RMS at KU, which was expected to be raised by the participants, is the fact that these tools do not 
support Arabic. In addition, not all the colleges at KU depend on English researches, some colleges are working on Arabic researches only such as Sharia and Islamic Studies College, or Arabic and French such as College of Law. In other words, not all research papers conducted at KU are in English, and if the RMS tools do not support Arabic, not all the faculty will need these tools. Which raises another issue: is there a need to Arabize these tools? This is an issue need to be explored on a regional level.

As a recommendation, especially for the KU library administration, the first step is to implement an overall awareness campaign of the RMS tools in general, then the available options that KU libraries offer and support. Several workshops are extremely needed, as indicated by respondents (both the users and non-users of RMSs). The library administration provides the RMS licenses and support, but they lack publicity and promotions for these services. For better engagement in the faculty process at the KU level, more training workshops are needed consistently. If a high awareness of RMSs among the faculty can be achieved, the next step will be to target graduate and undergraduate students.

\section{Conflicts of Interest}

The author declares no conflicts of interest regarding the publication of this paper.

\section{References}

[1] Francese, E. (2012) Reference Management Software as Digital Libraries: A Survey at the University of Torino. Master's Thesis, Oslo and Akershus University College of Applied Sciences, Oslo.

[2] Rakhshan, V. (2012) Reliance of Scientific Publication on Citation Management Software: The New Generation. Journal of Dental Research, Dental Clinics, Dental Prospects, 6, 158-159.

[3] Roux, W.L. and Burke, I. (2009) Collaborative Reference Management System. African Digital Scholarship and Curation Conference, Pretoria, 12-14 May 2009, $1-11$.

[4] Childress, D. (2011) Citation Tools in Academic Libraries: Best Practices for Reference and Instruction. References \& User Services Quarterly, 51, 53-62. https://doi.org/10.5860/rusq.51n2.143

[5] Lonergan, N. (2017) Reference Management Software Preferences among Liberal Arts Faculty. Reference Services Review, 45, 584-595. https://doi.org/10.1108/RSR-06-2017-0024

[6] Fitzgibbons, M. and Meert, D. (2010) Are Bibliographic Management Software Search Interfaces Reliable? A Comparison between Search Results Obtained Using Database Interfaces and the EndNote Online Search Function. The Journal of Academic Librarianship, 36, 144-150. https://doi.org/10.1016/j.acalib.2010.01.005

[7] Francese, E. (2013) Usage of Reference Management Software at the University of Torino. JLIS Journal of Library and Information Science, 4, 145-174.

[8] Basak, S.K. (2014) Reference Management Software: Comparative Analysis of RefWorks and Zotero. International Journal of Humanities and Social Sciences, 8, 
1987-1990.

[9] Hensley, M.K. (2011) Citation Management Software: Features and Futures. Reference \& User Services Quarterly, 50, 204-208. https://doi.org/10.5860/rusq.50n3.204

[10] Gilmour, R. and Cobus-Kuo, L. (2011) Reference Management Software: A Comparative Analysis of Four Products. Issues in Science and Technology Librarianship, 66, 63-75.

[11] East, J.W. (2001) Academic Libraries and the Provision of Support for Users of Personal Bibliographic Software: A Survey of Australian Experience with EndNote. LASIE (Library Automated Systems Information Exchange), 32, 64-70.

[12] Ram, S. and Anbu, K.J.P. (2014) The Use of Bibliographic Management Software by Indian Library and Information Science Professionals. Reference Services Review, 42, 499-513. https://doi.org/10.1108/RSR-08-2013-0041

[13] Parabhoi, L., Sahu, R.R. and Bhoi, N. (2018) Usefulness of Citation or Bibliographic Management Software: A Case Study of LIS Professionals in India. International Journal of Information Movement, 2, 55-61.

[14] Francese, E. (2011) The Usage of Reference Management Software (RMS) in an Academic Environment: A Survey at Tallinn University. International Conference on Integrated Information, Kos, 293-296.

[15] Sarrafzadeh, M. and Hazeri, A. (2014) The Familiarity and Use of Reference Management Software by LIS Faculties in Iran. New Library World, 115, 558-570. https://doi.org/10.1108/NLW-02-2014-0018

[16] Sarrafzadeh, M. (2017) Instruction of Citation Management Tools by Academic Librarians: The Need for Training the Trainers. Webology, 14, 53-65.

[17] Yıldırım, H. and Yılmaz, O. (2012) Analyses of Approaches of Academicians to Bibliographic Management Software (I.U. Faculty of Forestry Case). Journal of the Faculty of Forestry Istanbul University, 62, 53-70.

[18] Yilmaz, K. (2013) Comparison of Quantitative and Qualitative Research Traditions: Epistemological, Theoretical, and Methodological Differences. European Journal of Education, 48, 311-325. https://doi.org/10.1111/ejed.12014 
Appendix 1: Comparison of RMSs by Roux and Burke (2009) Shows the Developers, Cost and Requirements of These RMSs

\begin{tabular}{|c|c|c|c|c|c|c|}
\hline Software & Developer & $\operatorname{Cost}^{2}$ & Open Source & OS & $\begin{array}{l}\text { Export } \\
\text { Formats }\end{array}$ & Import Formats \\
\hline 2 collab & Elsevier & Free & No & All & $\begin{array}{c}\text { BibTeX, RIS } \\
\text { and CSV }\end{array}$ & $\begin{array}{l}\text { RIS and browser } \\
\text { bookmarks }\end{array}$ \\
\hline CiteULike & Richard Cameron & Free & No & $\begin{array}{l}\text { All, web- } \\
\text { based }\end{array}$ & $\begin{array}{l}\text { BibTeX, RIS } \\
\text { and Coins }\end{array}$ & BibTeX \\
\hline EndNote & Thomson Corp. & US\$299.95 & No & $\begin{array}{c}\text { Windows, Mac } \\
\text { OS }\end{array}$ & $\begin{array}{c}\text { BibTeX, } \\
\text { Medline, } \\
\text { BiblX, Refer, } \\
\text { RIS }\end{array}$ & $\begin{array}{l}\text { BibTeX (partially), } \\
\text { CSA, BiblX, III, } \\
\text { Medline, Ovid, } \\
\text { PubMed, RIS, } \\
\text { SciFinder }\end{array}$ \\
\hline JabRef & $\begin{array}{l}\text { JabRef } \\
\text { developers }\end{array}$ & Free & $\begin{array}{l}\text { Yes, GPL } \\
\text { License }\end{array}$ & All & $\begin{array}{c}\text { BibTeX, } \\
\text { BiblX, MODS } \\
\text { XML }\end{array}$ & $\begin{array}{l}\text { BibTeX (partially), } \\
\text { CSA, BiblX, III, } \\
\text { Medline, Ovid, } \\
\text { PubMed, RIS, } \\
\text { SciFinder }\end{array}$ \\
\hline refDB & refDB developers & free & $\begin{array}{l}\text { Yos, GPL } \\
\text { License }\end{array}$ & All & $\begin{array}{c}\text { BibTeX, } \\
\text { BiblX, MODS } \\
\text { XML, RIS }\end{array}$ & $\begin{array}{l}\text { BibTex, Compac, } \\
\text { ISI, Bib|X, MODS } \\
\text { XML, RIS, } \\
\text { PubMed }\end{array}$ \\
\hline RefShare $^{3}$ & Ivan Burke, CSIR & Free & $\begin{array}{l}\text { Yes, still only } \\
\text { prototype }\end{array}$ & $\begin{array}{l}\text { All, web- } \\
\text { based }\end{array}$ & BibTeX & BibTeX \\
\hline refBase & $\begin{array}{l}\text { Reference Base } \\
\text { Developers }\end{array}$ & free & $\begin{array}{l}\text { Yes, GPL } \\
\text { License }\end{array}$ & All & $\begin{array}{c}\text { BibTeX, } \\
\text { BiblX, MODS } \\
\text { XML, RIS }\end{array}$ & $\begin{array}{l}\text { BibTeX, Compac, } \\
\text { ISI, Bib|X, RIS, }\end{array}$ \\
\hline RefWorks & RefWorks & US $\$ 100$ per year & No & $\begin{array}{l}\text { All, web- } \\
\text { based }\end{array}$ & $\begin{array}{c}\text { BibTeX and } \\
\text { RIS }\end{array}$ & $\begin{array}{l}\text { BibTeX (partially), } \\
\text { CSA, BiblX, IVI, } \\
\text { Medline, Ovid, } \\
\text { PubMed, RIS, } \\
\text { SciFinder, MODS } \\
\text { XML }\end{array}$ \\
\hline
\end{tabular}

